\title{
Perceptions on the Quality of Life of Caregivers Caring for Older Adults With Alzheimer's Disease in Brazil: An Urgent Need for Social and Health Policies
}

\author{
Marina Celly Martins Ribeiro de Souza ${ }^{1}$, Diana Da Silva ${ }^{1}$, Natália de Cássia Horta ${ }^{2}$, Júnia Andressa Rodrigues \\ Melgaço $^{2}$, Lorraine Baêta Viana Martins ${ }^{2} \&$ Carolina Marques Borges ${ }^{1}$ \\ ${ }^{1}$ Department of Public Health, The College of New Jersey, Ewing, New Jersey, United States \\ ${ }^{2}$ Department of Medicine, Pontifical University of Minas Gerais, Belo Horizonte, Minas Gerais, Brazil \\ Correspondence: Marina Celly Martins Ribeiro de Souza, Department of Public Health, The College of New \\ Jersey, Ewing, New Jersey, United States.
}

Received: November 2, 2020

Accepted: December 19, 2020

Online Published: December 30, 2020

doi:10.20849/ijsn.v5i4.844

URL: https://doi.org/10.20849/ijsn.v5i4.844

\begin{abstract}
The aim of this research was to analyze the perceptions on the quality of life of caregivers who care for older adults with Alzheimer's disease. This study was conducted in the municipality of Betim, located in the metropolitan area of Belo Horizonte, Brazil. Thirty-two interviews were conducted with formal and informal caregivers. Data were organized into two empirical categories which affect the quality of life of caregivers: 1) older adult's familial support, and 2) the burden of caregiver's extensive workload. Results indicate that the quality of life of a caregiver can be elevated and improved through social support services provided by healthcare professionals, as well as health and social policies which allow a stronger support of caregivers through governmental programs.
\end{abstract}

Keywords: quality of life, caregiver, older adults, Alzheimer`s disease

\section{Introduction}

With the increase in the number of older adults in the world, the incidence of chronic diseases that affect mainly this population has grown in the past 50 years. In 2015, the number of people living with dementia worldwide was estimated at 47.47 million, reaching 135.46 million in 2050. Among these, Alzheimer's disease (AD), corresponds to $60 \%$ of dementia and is one of the most prevalent chronic degenerative diseases in Brazil. Alzheimer's disease causes progressive losses in the individuals' functional capacity, autonomy, and independence due to cognitive impairments, requiring the presence of a caregiver to assist them in their daily routines.

The caregiver is assigned several tasks that require dedication, responsibility, patience and, sometimes, even self-denial, leading to the caregiver often high levels of stress and overload. This fact may lead caregivers to experience a sense that their own life is suspended, 'on hold' in some way; that the uncertainty around the length and quality of the patient's survival affects wide-ranging areas of the caregiver's life as well. With this, the caregiver is subject to constant emotional oscillations that can generate distress around the individual with AD, and therefore, have to be prepared psychologically to care, without, however, affecting their own quality of life. The term "quality of life" discussed here is defined as the perception of the physical, mental and social well-being of the caregivers.

There comes a point, however, when the caregivers can reach or have already reached a point of exhaustion, and their quality of life can affect the older adult cared by them. In this sense, it is important to deeply comprehend how caregivers self-perceive their quality of life and ways in which health professionals could work on interventions that will support them.

Due to the relevance of Alzheimer's disease in the Brazilian context as an important public health problem, this study aims to understand the perceptions on quality of life of caregivers who take care of older adults with $\mathrm{AD}$ in Brazil, which may support the development of long-term care policies, still lacking in the country. 


\section{Methods}

This is a descriptive-exploratory research which uses a qualitative approach. The study was conducted in the metropolitan area of Belo Horizonte, which is the 3rd largest urban agglomeration in Brazil. The inclusion criteria for participating in this study was: 1) caregivers older than 18 years; 2) caring for older adults with a clinical diagnosis of Alzheimer's disease and, 3) a resident in the municipality of Betim, Brazil.

The interviews were carried out with 32 formal and informal primary caregivers of individuals with Alzheimer's disease identified in the Brazilian Universal Healthcare System using as a search criterion the International Code of Diseases (ICD) of the variants of Alzheimer's disease. A pilot test was carried out with the first 3 participants and the data collection was interrupted when new data no longer brought additional insights to the research questions.

Data collection was performed from July 2018 to April 2019 through semi-structured interviews created and applied by the researchers in the older adult's home. The researchers received support from the Brazilian Universal Healthcare System, specifically from the community health agents who led the researchers to the participants' homes.

The interviews lasted approximately 30 minutes and were recorded, typed and organized in order to describe the empirical investigation chart. The caregivers were coded as C1, C2, C3; etc., following the interviews' order. The material was analyzed by means of a thematic content analysis proposed by Bardin's Theory. Thus, first, each typed interview report was read and re-read to identify the most relevant and confounding aspects regarding the initial hypotheses of the project. Then, data were classified into empirical categories that had the ability to apprehend determinations and specifics expressed in the empirical reality, which were built based on the elements given by the social actor. From the qualitative data analysis two themes that supported the objective of this study emerged. To conclude, interpretations and articulations between the obtained data and the theoretical references were defined to answer the research questions based on their objectives.

Ethical principles were followed according to the Brazilian Resolution 466/12 of the National Research Council, regulating research with human beings, preserving the anonymity of all participants. The research followed the procedures of institutional authorizations and was approved by the Institutional Research Committee of the Pontifical Catholic University of Minas Gerais, Brazil. All participants had access to and signed the Informed Consent Form.

\section{Results and Discussion}

Participants included 31 women and 1 man (1 formal caregiver and 31 informal caregivers) with an average age of 54, ranging from 34-79 years, with a standard deviation of 12.1. The average amount of time that they provide care for older adults is about 20 hours a day, ranging from 8-24h a day, with a standard deviation of 4.2. The definition of "work" in this article refers to caregivers specifically caregiving for the older adult at home. This does not include outside work or secondary jobs.

The results found in the analysis of the interviews were divided into two categories: 1) "Older adults' familial support", and 2) "The burden of caregiver's extensive workload."

\subsection{Older Adults Familial Support}

It was observed that the majority of the participants had a positive perception of the older adult's familial support. The majority of the caregivers were related to the older adults, with relationships including, but not limited to, daughters, wives, daughters-in-law, sons, etc. In a multiple case study analyzing five countries on informal caregiving, it was mentioned that "sometimes coordination of care comes at a high cost and is an unbalanced equilibrium. If caregivers can no longer fulfill this role, other family members, friends, and neighbors are called to ensure the continuity of care." ${ }^{\prime 8}$. We observed that there were caregivers that had much familial support, and without their support, they believed that they would not be able to effectively care for their older adults.

[...] Yes, I have my son. My son is the one who helps me, and I have my daughter-in-law. [...] By ourselves we cannot do it, right? (C27).

Familial and/or outside support can help to alleviate the massive workload that caregivers have with their older adults. Support from others allows the caregiver to take breaks, eat, and/or run errands that they would not be able to do due to their intense work schedule. Support can also alleviate any stress that they may be feeling, which can affect their quality of life. In the multiple case study previously cited, it was shown from an interview in Belgium that "not all caregivers have support from their surroundings and this can have an impact on the level of emotional burden". Our findings support this argument through various caregivers exposing themselves and 
their lives on how they have been burdened with the extensive responsibility to provide care for these older adults 20 hours a day, 6 days a week, with no support.

Just support, I do not say all day or to stay all day, but there is no person in this case, because I do not have anyone [...] The more help, the more you can feel safer, right? Because he cannot just stay with any person. ff the Brazilian culture, it is shown that many Brazilians provide unpaid, 24/7 care for their family members as a way of life and is expected of them as their parents reach an older age and become ill and unable to work and care for themselves. A qualitative study comparing five different nationalities (Lebanese, Muslims, French, Paraguayans, Chinese, and Brazilians) on how filial care and the relationship with older adults occur in families, mentioned that among some Brazilians, the feeling of unity and the concern to remain close to their children prevailed. For them, aging within the family brings joy and satisfaction. It is expected from the older adult that their children will take care of them at the last stages of their lives:

My sadness is more due to my family's departure. This sadness is the greatest because the obligation of the children is to take care of the parents [...] because people think like this, that one day the children come to take care of their parents, right? Understood? Let's suppose, if I have seven siblings here, each one stays a month with her [...] they could do their day-to-day work, and could still enjoy their activities. But now I stand alone in this commitment, it's complicated, it's complicated. This makes me very distressed. (C21)

However, not all Brazilians who have parents over the age of 65 or more think this way. Care is not a well-established cultural habit in the country, which is probably related to the fact that it is still an eminently young country. This corroborates the argument in which caregivers feel burdened because they were expected to prepare for a task they were never warned about. This is possibly due to the fact that some older adults did not worry about educating and imparting the teachings to their children at a young age, perhaps for believing they would not reach longevity.

This cultural expectancy does not only derive from Brazil but is also common for other foreign children, such as Koreans. A mixed-method study on Korean-American cancer patients and their family caregivers showed that "although over a third of the caregivers provided 20 to 50 hours of care per week, hours of caregiving did not predict caregiver depression". Another qualitative study of Korean-American caregivers found that caregiving is viewed as an expected familial responsibility rather than a burden. The caregivers interviewed in that study understood that they needed to care for their family members, and some did not see it as a burden. However, the interviewees in the aforementioned study felt extremely burdened of caretaking because they had no one to help with the workload. Therefore, familial and/or outside support is, thus, essential for the quality of life of caregivers.

The interviews revealed that familial and/or outside support is essential for the quality of life of caregivers because it alleviates physical, emotional, and mental stressors, as well as the burdens which come with caregiving for older adults. A solution would be to provide stronger support systems for these familial caregivers through the national health care system. Health care professionals, especially nurses, would have the opportunity to provide training, workshops, and host conferences either in person or online (if the caregiver cannot leave home) on how to care for the older adult but to also take care of one. It is important to highlight that the vast majority of the caregivers who participated in our study never received any type of formal training on how to take care of an older adult. It is necessary that there is a network of support that guarantees the basic care not only for the older adult but also for their caregivers.

There is also the factor that not all older adults have children, and therefore the question would be who then would be responsible for taking care of them? Given that under the Brazilian constitution, health is a right and not a privilege, public policies need to be established for the right of older adults who have no offspring on ways in which they will be provided with care from governmental programs and long-stay institutions.

\subsection{The Burden of Caregivers Extensive Workload}

The caregivers in our study worked an average schedule of 20 hours a day, 6 days a week. This extensive workload includes giving medicine, cooking, feeding, cleaning, and watching the older adult who is under their care:

I was just explaining that I cannot take it anymore, to keep carrying him, because I am the only one who helps pick him up, both myself and my sister [...] My sister cannot handle it, she already has a broken clavicle. I already have a problem in my bones, I also feel the pain of carrying weight, carrying him [...] It has become very difficult for us. (C8).

There is a daughter, a niece, only, and they coming here helps a lot (C6). 
Many of these caregivers are not fit to do the intense tasks of carrying these older adults because of their age and/or their inability to lift heavy weight. Some of these older adults also cannot be left alone because they may fall or wander off outside, and because of their Alzheimer's disease, they would not be able to get back home. Caregivers may face the daunting task of providing care for a loved one who can no longer recognize themselves. As the disease progresses, behavioral and psychological symptoms such as agitation, aggression, depression, anxiety, and other problems reportedly occur in almost all individuals; these can be a major source of stress and burden for caregivers. This intense workload has caused caregivers to become extremely tired, trapped in their own homes because they have to stay indoors with the older adult all-day every day, and can become depressed because they spend the majority of their time and energy with their older adults.

In the beginning I lost all rationale, I truly did. Speaking for myself, I am going to tell you that I almost went crazy, because we do not understand what is going on right there at the moment because she suddenly becomes very aggressive, you know? [...] just like that, I thought I was losing my mind [...] (C19).

An intense workload can drastically affect the quality of life of a caregiver because they stop prioritizing and taking care of them, in order to care for the older adult. The feelings of tiredness, emotional and physical exhaustion are commonly related to the burnout syndrome. The burnout syndrome is a response to chronic work-related stress comprising three components or dimensions: emotional exhaustion, depersonalization, and personal accomplishment. Individuals suffering from burnout usually manifest psychosomatic problems (weakness and insomnia), emotional problems (anxiety and depression), attitude pro-problems (hostility, apathy and distrust) and behavioral problems (aggressiveness, irritability and isolation).

A similar study on care burden and self-efficiency on caregivers for older adults was conducted in Turkey, where it was reported that $33.33 \%$ of the caregivers had effects on their psychological status and led to anger and frustration. The research suggests that caregivers experience depression, emotional difficulty, social isolation, and health-related problems much more frequently than those who do not care for their older adults.

Other caregivers have expressed how they have lost their autonomy - not being able to do things for themselves, feeling trapped and not being able to leave the house.

All day, day and night, you know? Lately, I'm not doing anything, because even leaving the house is difficult, you know? When caring for people like that, it is hard to leave home [...] It's the issue of us being stuck here. (C15).

When analyzing the interviews, we noticed that many of the caregivers were not able to have time for themselves, develop hobbies, or enjoy any activities because of the amount of dedication they needed to put into caring for the older adults. Additionally, the caregivers must manage several factors relating directly to a patient's illness together with other 'secondary stressors' such as changing roles, disruption to lifestyle and family functioning, changes to relationships and sense of self, concerns regarding their own and the patient's employment with the associated financial implications. Ultimately, these caregivers have the feeling that they are not living their own life, but rather just playing the role which the society expects them to do.

Therefore, the quality of life of an older adult is thus dependent on the one who is providing care for them. These older adults with Alzheimer's disease are dependent on their caregivers. They are in constant need to 24-hour care, which varies in responsibility from one to another. The caregiver plays one of the most essential part in the quality of life of the older adult because they are the providers of care. If the caregiver's quality of life is diminished; malnourished, depressed, anxious, weak physically and emotionally, and has limited resources, then both qualities of life will begin to decline. It is thus important to remember that the quality of life of an older adult is reflective of the quality of life of the caregiver, for they can only deliver what they have.

\section{Limitations}

There were a few limitations to this study. Firstly, the interviews were conducted in the home of individuals with Alzheimer's disease, to approach the participants' reality and to avoid their commute. Due to this, to obtain the addresses of the older adults and to visit areas of high social vulnerability, the researchers depended on the availability of Community Health Agents, thus being a limitation in data collection. Secondly, caregivers were not always available from their care-related activities, performing multitasking during the interviews. Thirdly, this study's findings cannot be generalized to other study population or community with different characteristics. 


\section{Conclusion}

This study shows that the quality of life of a caregiver is essential for the quality of life of the older adult under their care. If the caregiver is not emotionally, physically, mentally and/or spiritually stable to care for themselves, the quality of care delivered will be compromised. In conclusion, the quality of life of a caregiver should be elevated and improved through social support services provided by healthcare professionals, and health and social policies which will allow a stronger support of caregivers through governmental programs in Brazil.

\section{References}

Adriaenssens, J., De Gucht, V., \& Maes, S. (2012). The impact of traumatic events on emergency room nurses: Findings from a questionnaire survey. International Journal of Nursing Studies, 49(11), 1411-1422. https://doi.org/10.1016/j.ijnurstu.2012.07.003

Bardin, L. (2009). Análise de Conteúdo. Lisboa: Edições, 70(3).

Faller, J. W., Zilly, A., Alvarez, A. M., \& Marcon, S. S. (2017). Cuidado filial e o relacionamento com o idoso em famílias de diferentes nacionalidades. Revista Brasileira de Enfermagem, 70(1), 22-30. https://doi.org/10.1590/0034-7167-2015-0050

Fletcher, B. S., et al. (2012). The cancer family caregiving experience: An updated and expanded conceptual model. European Journal of Oncology Nursing, 16(4), 397-398. https://doi.org/10.1016/j.ejon.2011.09.001

Han, H. R., Choi, Y. J., Kim, M. T., Lee, J. E., \& Kim, K. B. (2008). Experiences and challenges of informal caregiving for Korean immigrants. Journal of Advanced Nursing, 63(5), 517-26. https://doi.org/10.1111/j.1365-2648.2008.04746.x

Hendriksen, E., Williams, E., Sporn, N., Greer, J., DeGrange, A., \& Koopman, C. (2015). Worried together: a qualitative study of shared anxiety in patients with metastatic non-small cell lung cancer and their family caregivers. Supportive Care in Cancer, 23(4), 1035-1041. https://doi.org/10.1007/s00520-014-2431-9

Jansson-Fröjmark, M., \& Lindblom, K. (2010). Is there a bidirectional link between insomnia and burnout? A prospective study in the Swedish workforce. International Journal of Behavioral Medicine, 17(4), 306-313. https://doi.org/10.1007/s12529-010-9107-8

Leape, L. L., Shore, M. F., Dienstag, J. L., Mayer, R. J., Edgman-Levitan, S., Meyer, G. S., ... Healy, G. B. (2012). Perspective: a culture of respect, part 1: the nature and causes of disrespectful behavior by physicians. Academic Medicine, 87(7), 845-852. https://doi.org/10.1097/ACM.0b013e318258338d

Lopez, O. L., \& Kuller, L. H. (2019). Epidemiology of aging and associated cognitive disorders: Prevalence and incidence of Alzheimer's disease and other dementias. In Handbook of clinical neurology. Elsevier. https://doi.org/10.1016/B978-0-12-804766-8.00009-1

Maslach, C., \& Jackson, S. E. (1981). The measurement of experienced burnout. Journal of Organizational Behavior, 2(2), 99-113. https://doi.org/10.1002/job.4030020205

Miller, L. E. (2012). Sources of uncertainty in cancer survivorship. Journal of Cancer Survivorship, 6(4), 431-440. https://doi.org/10.1007/s11764-012-0229-7

Minayo, M. C. D. S., Deslandes, S. F., \& Gomes, R. (2010). Pesquisa social: teoria, método e criatividade. Editora Vozes Limitada.

Nogales-González, C., Romero-Moreno, R., Losada, A., Márquez-González, M., \& Zarit, S. H. (2015). Moderating effect of self-efficacy on the relation between behavior problems in persons with dementia and the distress they cause in caregivers. Aging \& Mental Health, 19(11), 1022-1030. https://doi.org/10.1080/13607863.2014.995593

Olson, R. E. (2014). Indefinite loss: the experiences of care of a spouse with cancer. European Journal of Cancer Care, 23(4), 553-561. https://doi.org/10.1111/ecc.12175

Patti, F., Amato, M., Battaglia, M., Pitaro, M., Russo, P., Solaro, C., \& Trojano, M. (2007). Caregiver quality of life in multiple sclerosis: A multicenter Italian study. Multiple Sclerosis Journal, 13(3), 412-419. https://doi.org/doi:10.1177/1352458506070707

Prince, M., Wimo, A., Guerchet, M., Ali, G. C., Wu, Y. T., Prina, M., \& World Alzheimer Report. (2015). The global impact of dementia: an analysis of prevalence, incidence, cost and trends. London, England: Alzheimer's Disease International. 
Pudelewicz, A., Talarska, D., \& Bączyk, G. (2019). Burden of caregivers of patients with Alzheimer's disease. Scandinavian Journal of Caring Sciences, 33(2), 336-341. https://doi.org/10.1111/scs.12626

Shilling ,V., et al.. (2017). The pervasive nature of uncertainty - a qualitative study of patients with advanced cancer and their informal caregivers. Journal of Cancer Survivorship, 11(5), 590-603. http://doi.org/10.1007/s11764-017-0628-x

Shilling, V., Starkings, R., Jenkins, V., Cella, D., \& Fallowfield, L. (2019). Development and validation of the caregiver roles and responsibilities scale in cancer caregivers. Quality of Life Research, 28(6), 1655-1668. https://doi.org/10.1007/s11136-019-02154-4

Unver, V., Basak, T., Tosun, N., Aslan, O., \& Akbayrak, N. (2016). Care burden and self-efficacy levels of family caregivers of elderly people in Turkey. Holistic Nursing Practice, 30(3), 166-173. https://doi.org/10.1097/HNP.0000000000000148

Willemse, E., Anthierens, S., Farfan-Portet, M. I., Schmitz, O., Macq, J., Bastiaens, H., \& Remmen, R. (2016). Do informal caregivers for elderly in the community use support measures? A qualitative study in five European countries. BMC Health Services Research, 16(1), 270-278. https://doi.org/10.1186/s12913-016-1487-2

Wolk, D. A., \& Dickerson, B. C. (2016). Clinical features and diagnosis of Alzheimer disease. Waltham, MA.

Yoon, H., Chatter, L., Kao, T. S. A., Saint-Arnault, D., \& Northouse, L. (2018). Predictors of quality of life and depression among Korean-American cancer patients and their family caregivers. Psycho-Oncology, 27(12), 2717-2724. https://doi.org/10.1002/pon.4864

\section{Copyrights}

Copyright for this article is retained by the author(s), with first publication rights granted to the journal.

This is an open-access article distributed under the terms and conditions of the Creative Commons Attribution license (http://creativecommons.org/licenses/by/4.0/). 